more or less co-extensive with the present coalfields, receive no support from Renier's work.

In contrast with the uniformity of the floors of the coal seams, the roofs yield extremely varied faunas and floras. These have been examined and recorded with great precision. Renier quotes approvingly the words of Crépin, who laid down two rules for palæontologists working on the coal measures so long ago as 1878. Palæontologists, he advised, should never confine their researches to material collected from the rubbish tips of collieries, but should themselves descend the mines and study the Carboniferous vegetation in situ ; further, they ought not to leave the collecting exclusively to workmen and others ignorant of the science, but to undertake some of the labours themselves.

The neglect of this advice-not only in Belgiumled for many years to serious errors in regard to the palæontology of the coal measures. Thus, Prof. Renier shows that certain palæontologists who have studied the coal measures of Belgium since Crépin's time based their conclusions almost entirely on museum collections, and decided that the flora was uniform in character from top to bottom of the sequence; recent work, on the other hand, based on the actual examination of each horizon, has made it clear that distinct floras can be recognised and used both in the identification of seams and in the correlation of the coal measures over western Europe.

Prof. Pruvost's account of the non-marine faunas makes a fitting sequel to his monumental work on the faunas of the coal measures of the north of France. A beautiful series of plates is devoted chiefly to the fossil insects and other arthropods and to the fishes. A number of remarkable fossils is described, and this part of the memoir will be indispensable to all students of coal measure palæontology. It is much to be regretted that no illustrations of any of the Mollusca are included (except in relation to their supposed borings ; the Mollusca are much more frequent than other fossil animals at most horizons, and Pruvost relies on them to a great extent in his correlation.

Pruvost is not prepared, however, to accept any of the refinements in nomenclature which have been made in recent years. To a large extent he has followed the late Dr. Wheelton Hind, who was very conservative (and sometimes, unfortunately, rather inaccurate) in his interpretation of these species. But whereas even the latter was willing to recognise some twenty-five species of non-marine lamellibranchs in the coal measures of Belgium, Pruvost admits no more than twenty. In his 'lumping' of species he places Anthracomya librata Wright as a synonym of Carbonicola similis Brown, and Naiadites elongata Hind as a synonyom of Anthracomya phillips Will. It is probable that his discrimination of the faunas is much more precise than the nomenclature which he uses, but his method must make it difficult for other palaeontologists to make full use of his labours.
A. E. Trueman.

\title{
Dyestuffs and Enzymes.
}

M ANY dyes and related compounds have a specific toxic effect on certain micro-organisms which has been utilised in the treatment of the diseases caused by them. The mode of action of the dyestuff is not known, but it is probable that it poisons some particular system in the cell, without which the latter cannot carry on its metabolic activities.

Some recent researches by J.H. Quastel on the action of dyes upon enzymes may throw light not only on the nature of the toxic effect, but also on the constitution of the enzymes employed (Biochem. Jour., vol. 25, p. 629 ; 1931 (with A. H. M. Wheatley); and ibid., vol. 25 , pp. 898 and 1121 ; 1931). In the first paper it was found that basic, but not acid, dyes inhibited the oxygen uptake by $B$. Coli in the presence of glucose, lactate, succinate, and formate. The degrees of inhibition varied both with the dye and the substrate used, so that the effect could not be due to a general lethal action. Since it is the basic dyes which are active, it appears that the cell dehydrogenases are essentially acidic in character; but basicity is not the only factor in toxicity, since the basic Bismarck brown has little action. The inhibitory action of the dye was less marked in phosphate than in veronal buffer. Similar results were obtained with muscle enzymes, but no inhibition was observed with any dye when brain tissue was used, probably because the dye failed to reach the enzyme.

In the second paper, the behaviour of fumarase from micro-organisms or from brain or red-blood cells was studied. This enzyme converts fumarate to $l$ malate, which can be estimated polarimetrically. It was found that both acid and basic dyes were toxic, but a marked specificity was apparent ; of the former, the Congo red series was the most toxic, of the latter, the triphenylmethane series. It was also observed that fumarate combines with its enzyme and prevents the combination, and hence the toxic action, of both acid and basic dyes; that proteins exert a protective action, and that the protective action of phosphates is less than in the case of the dehydrogenases.

The most recent experiments have been carried out with certain naphthylaminedisulphonic acids and fumarase, after observing that trypan red and Bayer 205, like Congo red and trypan blue, are toxic. None of the six acids tested were toxic, nor were their first $s$-carbamide derivatives. The second and especially the third $s$-carbamide derivatives were, however, very toxic, that is, the $s$-carbamides of $m$-aminobenzoylnaphthylaminedisulphonic acid and of $m^{\prime}$-aminobenzoyl - $m$ - aminobenzoylnaphthylamine - disulphonic acid. The importance of this observation lies in the fact that there is a definite, though not strict, parallelism between the toxic action of these carbamides on fumarase and their trypanocidal potency, as determined by Balaban and King. It is possible that this method of investigating the toxicity of dyestuffs on enzymes may prove suitable for preliminary tests in the preparation of compounds likely to be of chemotherapeutic value.

\section{Carbonisation of Coal.}

GREAT expectations have been placed upon coal carbonisation at low temperatures as a source of motor spirit. Fuel Research Technical Paper No. 34 (H.M.S.O., 6d. net), on the "Light Spirits from the Low Temperature Carbonisation of Coal", shows that the experience with benzole production cannot be directly transferred to low temperature products.

No. 3244, VoL. 129]
The proportion of tar acids and unsaturated compounds is higher, necessitating greater consumption of chemicals in refining. The refined products were found by actual tests in petrol engines to be good motor fuels at least equal, when fresh, to commercial petrol. They still contained considerable quantities of unsaturated compounds which were liable to polymerise 
on storage and they show increased gum and peroxide formation, accompanied by decrease in the highest useful compression ratio (H.U.C.R.). The report suggests the need for caution in assessing the value of low temperature processes as sources of motor fuel.

The pioneers of low temperature carbonisation seemed to take it for granted that the tars and oils produced would find markets ready for their absorption. Even now, this idea is still widespread. Experience brought disillusion, and it became clear that only after long research could one expect to develop uses for these novel products. Among other institutions the Fuel Research Station has studied systematically the influence of conditions on the general character of the tars and liquors. A more detailed chemical study of the tars was undertaken by the National Chemical Laboratory at Teddington with the view of discovering, if possible, new industrial applications for these products.

Much of this work has been published in periodicals and is now included in a Fuel Research Technical Paper No. 32, entitled "A Study of the Tars and Oils Produced from Coal" (H.M.S.O., 2s, net). This is in four parts : statistics, the treatment of low temperature tars from a commercial retort, the carbonisation of three British coals at varying temperatures, and the influence of temperature on the properties of tars. Perusal leads to the conclusion that in the development of low temperature processes too much capital has been spent on large scale plant, and too little on laboratory investigation of the chemistry of the processes and their products.

One branch of the work of the Fuel Research Board is the physical and chemical survey of national coal resources, which now covers practically the whole of the British coalfields. The reports hitherto published have dealt with the detailed survey of seams of coal. Paper No. 20, which has just appeared (H.M.S.O., 1s. 3d. net), entitled "The Yorkshire, Nottinghamshire and Derbyshire Coalfield, Analysis of Commercial Grades of Coal, Part I.", breaks new ground by giving the analyses of the commercial products of about forty important collieries in the district. It can scarcely be doubted that the information will be of great use to those concerned with the selection and purchase of coal, whether at home or abroad. The report should also be of great value to the collieries concerned, and will excite envy in other industries not so fortunate as to have their products so examined and certified. Perhaps the most striking impression which the reader can gain from the figures is the high quality of the fuel marketed in this area. Most of the samples contain less than five per cent of ash.

\section{High Speed Flying.}

$\mathrm{A}^{\mathrm{T}}$ an evening discourse delivered before members of the British Association on Sept. 29, Mr. H. E. Wimperis, Director of Scientific Research to the Air Ministry, gave an interesting résumé of accom. plishments, and speculations as to future advances, in high speed flying. The very high accelerations set up have given rise to various problems, both structural in the aircraft and physiological in the occupant. A rate of three times that of gravity can be obtained in starting by the use of catap lts. These are necessary for obtaining the minimum speed for flight for fast machines in a reasonable space. It is interesting to note that this rate of increase of speed is about a hundred times that of a steam-engined railway train. Even greater accelerations are experienced in curved flight-up to five times gravity - and as the machine is only designed to withstand a load of $8 g$, care has to be exercised, in making rapid turns of small radius, not to approach this. The centrifugal force on the pilot in such turns drives the blood from his brain to the more distensible parts of his body, and this is ac. companied by a loss of sight, although not of mental clarity.

Such high speed machines are necessarily built as seaplanes, as it is impossible to make aerodromes with sufficiently flat surfaces, or large enough, to allow of reaching the very high minimum flying speed with safety. Even on smooth water, handling requires considerable skill, as the angle at which the floats will leave the water due to hydro-planing is greater than the machine can maintain when it becomes air borne. Another peculiar trouble arises from the fact that at speeds of above $360 \mathrm{~m} . \mathrm{p} . \mathrm{h}$. the rush of air actually heats a body passing through it, instead of cooling it. This complicates the question of cooling both the engine and the pilot's cockpit.

With regard to future progress, while there is no theoretical limit to speeds higher than 407.5 m.p.h., the present record, there are many practical difficulties to be overcome. Better streamlining would give up to another $60 \mathrm{~m}$.p.h. for the same power, but some excrescences which spoil this, such as the undercarriage, tail, etc., appear to be inevitable. At the velocity of sound, namely, about 700 m.p.h., there is a doubling of the head resistance, which would appear to be an insurmountable barrier to aircraft of the present form, but with other aerodynamic outlooks this may be passed.

Another method of reducing resistance would be to fly at altitudes of, say, 100,000 feet, where the reduced density of the air would offer less resistance to motion. This would probably need some form of rocket propulsion, as the present-day engine would not function without a sufficient supply of oxygen, neither would the propeller have enough bite on the thin air to transmit the necessary thrust.

\section{Hardening of Metals in a Magnetic Field.}

$M^{2}$ R. E. G. HERBERT, of Manchester, contributed a paper to the Royal Society in January 1931 and two articles to Metallurgia in May and June of last year on the hardening of metals in a magnetic field. The Royal Society paper describes the fluctuations in the hardness of steel, duralumin, and brass caused by rotation in a magnetic field. Mr. Herbert shows that the time element is an important factor in the harden. ing produced magnetically. He has found that the hardness changes are sometimes very rapid, and in hard steel, freshly treated, changes may sometimes be observed from minute to minute.
Later research has shown that the effect produced in steel by the magnetic treatment is periodic in character, generally extending over many hours sub. sequent to treatment. In some experiments there were a sequence of six alternate increases and decreases of hardness occupying gradually lengthening periods of time. It was found that when a rotary magnetic field was used the maximum hardening effect could be produced by a single turn in the magnetic field at a suitable temperature followed by a period of ageing. The cloud-burst process of hardening by steel ball bombardment could be superimposed on the 